\title{
Valence tautomerism and recyclisation of type B mesoionic tetrazoles: a computational study
}

\author{
Wojciech Piotr Oziminski ${ }^{1}\left[\right.$ Christopher Antony Ramsden ${ }^{2}[$
}

Received: 19 July 2021 / Accepted: 15 September 2021 / Published online: 29 September 2021

(c) The Author(s) 2021

\begin{abstract}
The energy profiles for ring opening of representative type B mesoionic 2,3-diphenyl-1,2,3,4-tetrazolium-5-olates, -thiolates, -aminides and -methylides and for alternative recyclisation pathways are investigated using ab initio MP2 calculations. The energetics of initial ring opening are found to be comparable for all systems, but the tetrazolium-5-olates are anomalous in that no alternative reaction pathway is accessible. The influence of solvent is explored using the polarised continuum model (PCM) method to simulate aqueous solvation. The only significant solvent effect is found to be solvation of the mesoionic precursors. This solvent effect correlates with dipole moment and disfavours initial valence tautomerism both kinetically and thermodynamically.
\end{abstract}

Keywords Mesoionic $\cdot$ MP2 Calculations $\cdot$ Valence tautomerism $\cdot$ Tetrazoles $\cdot$ Solvation $\cdot$ Recyclisation

\section{Introduction}

To gain a better understanding of the reaction pathways available to type $\mathrm{B}$ mesoionic tetrazoles, we have undertaken an MP2 ab initio study of the energy barriers to ring opening and recyclisation. We have previously studied the relative energies of ten type B mesoionic rings $\mathbf{1}$ and their valence tautomers 2 . The stability of the ring increases with increasing strength of the single bond $\mathrm{W}-\mathrm{W}(\mathrm{S}-\mathrm{S}>\mathrm{RN}-\mathrm{NR}>\mathrm{O}-\mathrm{O})$ and with aza substitution $(\mathrm{X}=\mathrm{N})[1]$.

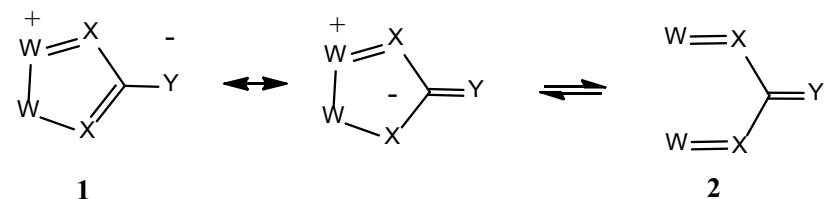

Wojciech Piotr Oziminski

wojciech.oziminski@wum.edu.pl

Christopher Antony Ramsden

c.a.ramsden@keele.ac.uk

1 Faculty of Pharmacy, Medical University of Warsaw, 1 Banacha Street, 02-097 Warsaw, Poland

2 Lennard-Jones Laboratories, School of Physical and Geographical Sciences, Keele University, Staffordshire ST5 5BG, UK
The earliest report of an example of this class of heterocycle was the preparation of dehydrodithizone 3a by Fischer and Bestorn (1882) [2]. A preparation of the exocyclic oxygen analogue 3b was first reported by Bamberger (1898) [3, 4]. Other 1,2-diphenyl analogues are known. The exocyclic imine derivative $\mathbf{3 c}$ was described by Bamberger et al. [5] in 1926 but, as with derivatives 3a,b, only later was the mesoionic structure recognised [6]. The carbon analogue $\mathbf{3 d}$ was described by Neugebauer and Fischer (1980) but formulated as the tautomer $\mathbf{4 d}$ [7]. Based on spectral data $\left(\lambda_{\max } 425\right)$ and the relative stability of closely related mesoionic tetrazoles, the open-chain structure $\mathbf{4 d}$ is only a transient intermediate in the formation of the mesoionic derivative 3d. Araki et al. in an NMR study have shown that the nitrile analogue $\mathbf{3 e}\left(\lambda_{\max }\right.$ 468 ) is strongly favoured over the acyclic tautomer $4 \mathbf{e}$ [8].<smiles>[Y]c1nn(-c2ccccc2)[n+](-c2ccccc2)n1</smiles>

3

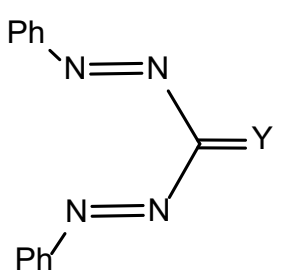

4
In structures 3 and $\mathbf{4 :}$
a, $\mathrm{Y}=\mathrm{S} ; \mathrm{b}, \mathrm{Y}=\mathrm{O} ; \mathrm{c}, \mathrm{Y}=\mathrm{N} . \mathrm{NO} ; \mathrm{d}, \mathrm{Y}=\mathrm{CH} . \mathrm{NO}$;
$\mathrm{e}, \mathrm{Y}=\mathrm{C}(\mathrm{CN})_{2}$ 
Scheme 1 The mode of recyclisation of the acyclic valence tautomers 5

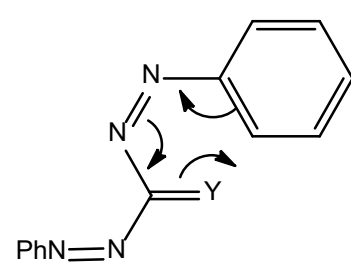

5

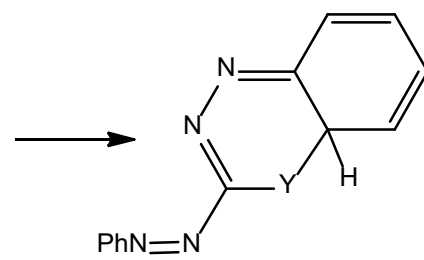

6

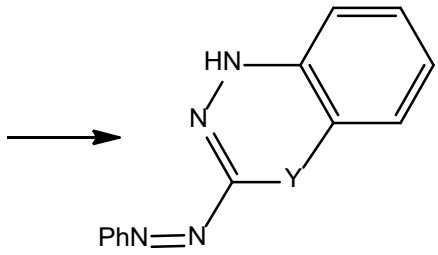

7

In structures 5 and 7:

a, $\mathrm{Y}=\mathrm{S} ; \mathrm{b}, \mathrm{Y}=\mathrm{O} ; \mathrm{c}, \mathrm{Y}=\mathrm{N} . \mathrm{NO} ; \mathrm{d}, \mathrm{Y}=\mathrm{CH} . \mathrm{NO}$

Much of the chemistry of the mesoionic tetrazole derivatives $\mathbf{3 a}, \mathbf{c}, \mathbf{d}$ can be rationalised in terms of initial ring opening to the corresponding tautomers $\mathbf{4 a}, \mathbf{c}, \mathbf{d}$. Dehydrothizone 3a is thermally transformed to the benzothiadiazin isomer 7a [9], which is almost certainly formed by recyclisation of a rotamer $5 \mathbf{a}$ to the intermediate $\mathbf{6 a}$ followed by proton transfer (Scheme 1). In a separate series of studies, Boyd et al. have provided evidence that the tautomer 5a can be trapped by 1,4-cycloaddition across the diazothione fragment [10-12].

In a re-examination of the work of Bamberger et al. [5], the derivative $\mathbf{3 c}$ has been shown to thermally rearrange to the $\mathrm{N}$-oxide $9 \mathbf{a}$, which is rationalised by recyclisation of the transient tautomer 8a (Scheme 2) [13, 14]. A similar mechanism accounts for the triazole $\mathbf{1 0}$ accompanying formation of the tetrazole 3d [7]. The mode of deoxygenation of the $\mathrm{N}$-oxide precursor $\mathbf{9 b}$ is not clear.

Although the tetrazolium-4-olate $\mathbf{3 b}$ has been known for over 120 years, surprisingly, its chemistry is limited to salt formation $[15,16]$. In contrast to its close analogue $\mathbf{3 a}$, there is no experimental evidence of valence tautomerism $(\mathbf{3} \rightleftharpoons \mathbf{4})$. We now report a study of the energy barriers associated with reaction pathways available to the mesoionic tetrazole derivatives 3a-d.

\section{Results and discussion}

Figure 1 shows the generalised energy profile for the ring opening of type B mesoionic rings $\mathbf{3}$ and recyclisation to the bicyclic products 7. Energy values (Hartrees) and energy differences $\left(\mathrm{kcal} \mathrm{mol}^{-1}\right)$ for the derivatives 3-7 $(\mathrm{Y}=\mathrm{S}, \mathrm{O}, \mathrm{N} . \mathrm{NO}$, CH.NO) and transition states $\mathbf{T} \mathbf{1}$ and $\mathbf{T} 2$ are given in Table 1.

\section{Gas phase MP2 calculations}

The calculated activation energies $\boldsymbol{\Delta} \mathbf{G}_{\mathbf{3 T 1}}$ for ring opening via the transition state T1 (Table 1, Entries 1-4) are all in the range $26-31 \mathrm{kcal} \mathrm{mol}^{-1}$. Since there is strong experimental evidence that the derivatives $\mathbf{3 a}, \mathbf{c}, \mathbf{d}$ do undergo thermal valence tautomerism in solution $(\mathbf{3} \rightleftharpoons \mathbf{4})$, it is unlikely that the oxygen analogue $\mathbf{3 b}$ will not undergo ring opening under similar conditions. As previously reported [1], the energy differences between the valence tautomers $\mathbf{3 a}, \mathbf{b}, \mathbf{c}$ and $\mathbf{4 a}$, $\mathbf{b}, \mathbf{c}\left(\Delta \mathbf{G}_{\mathbf{3 4}}\right)$ are in the range $16-18 \mathrm{kcal} \mathrm{mol}^{-1}$. Interestingly, the $\mathbf{\Delta} \mathbf{G}_{\mathbf{3 4}}$ value for the exocyclic carbon analogue $\mathbf{3 d}$ $\left(10.29 \mathrm{kcal} \mathrm{mol}^{-1}\right)$ is much less. We attribute this to the lower electronegativity of carbon providing less stabilisation of the exocyclic negative charge in the mesoionic structure 3d. As might be expected, this also lowers the calculated activation energy $\mathbf{\Delta} \mathbf{G}_{\mathbf{3 T 1}}\left(26.18 \mathrm{kcal} \mathrm{mol}^{-1}\right)$.
Scheme 2 The alternative mode of recyclisation of the nitroso valence tautomers 8

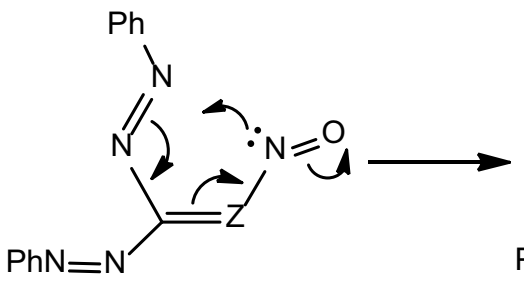

8

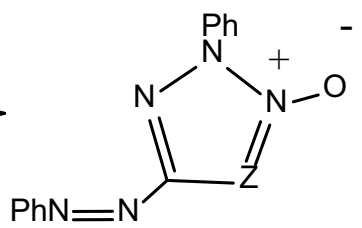

9<smiles>Pc1cccc(N=Nc2cn[nH]n2)n1</smiles>

10

In structures $\mathbf{8}$ and $\mathbf{9}$;

$\mathrm{a}, \mathrm{Z}=\mathrm{N} ; \mathrm{b}, \mathrm{Z}=\mathrm{CH}$ 
Fig. 1 Generalised energy profile for the conversion of the mesoionic tetrazoles 3 to the products 7

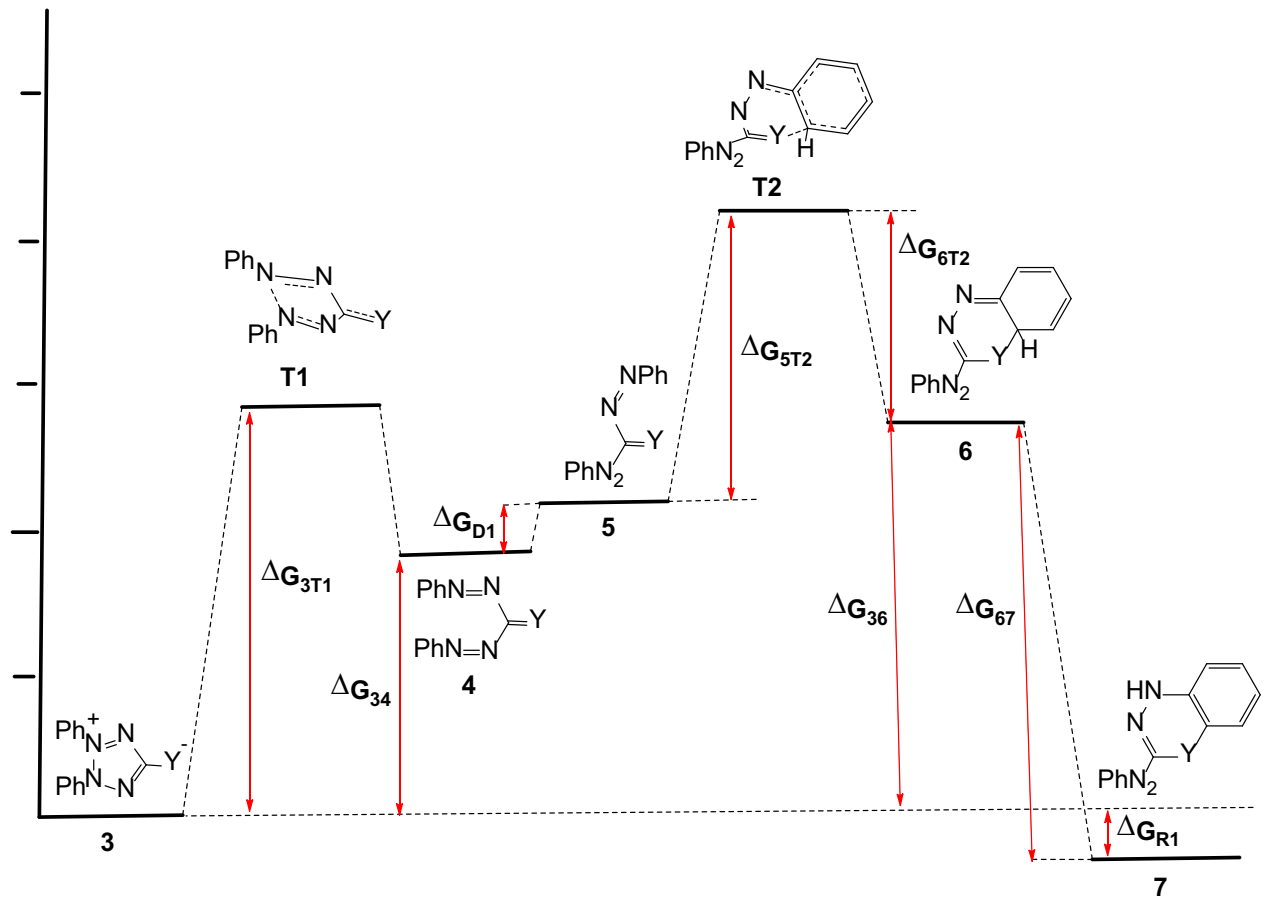

To undergo an electrocyclic ring closure to give the intermediates 6, the valence tautomers $\mathbf{4}$ must equilibrate with a higher energy rotamer $\mathbf{5}$. The energy differences $\boldsymbol{\Delta} \mathbf{G}_{\mathbf{D} \mathbf{1}}$ are in the range $3.5-7.3 \mathrm{kcal} \mathrm{mol}^{-1}$. A particularly significant difference between the sulphur and oxygen derivatives is the activation energy for electrocyclic ring closure $\left(\Delta \mathbf{G}_{\mathbf{5 T 2}}\right)$. The sulphur tautomer $\mathbf{5 a}$, known to lead to the isolated product 7a, has an activation energy $\boldsymbol{\Delta} \mathbf{G}_{\mathbf{5 T 2}}$ of $20.74 \mathrm{kcal} \mathrm{mol}^{-1}$ (Table 1). In contrast, the oxygen analogue $\mathbf{5 b}$ has a significantly higher $\boldsymbol{\Delta} \mathbf{G}_{\mathbf{5 T 2}}$ value of $31.99 \mathrm{kcal} \mathrm{mol}^{-1}$. Like the transition state, the oxygen intermediate $\mathbf{6 b}$ is also correspondingly higher in energy relative to the precursor $\mathbf{5 b}$ than the corresponding sulphur intermediate $\mathbf{6 a}$. This is reflected in the reverse activation energies $\Delta \mathbf{G}_{\mathbf{6 T} 2}$ (Table 1). These differences in the thermodynamics of the ring closures $5 \mathbf{a}, \mathbf{b}$ to $\mathbf{6 a}, \mathbf{b}$ have the consequence that the oxygen intermediate $\mathbf{6 b}$ is $43.47 \mathrm{kcal} \mathrm{mol}^{-1}\left(\boldsymbol{\Delta} \mathbf{G}_{\mathbf{3 6}}\right)$ higher in energy than the starting material $\mathbf{3 b}$ whereas the sulphur intermediate $\mathbf{6 a}$ is only $26.35 \mathrm{kcal} \mathrm{mol}^{-1}\left(\mathbf{\Delta G}_{\mathbf{3 6}}\right)$ higher in energy. Since the energy of prototropic transfer $(\mathbf{6} \rightarrow \mathbf{7})$ is almost the same for both species $\left(\boldsymbol{\Delta}_{\mathbf{6}} ; \mathbf{6} \mathbf{6} 27.35\right.$ and $6 \mathbf{b} 26.62 \mathrm{kcal} \mathrm{mol}^{-1}$ ), it follows that the overall reaction of the sulphur derivative $(\mathbf{3 a} \rightarrow \mathbf{7 a})$ is calculated to be weakly exothermic $\left(\Delta \mathbf{G}_{\mathbf{R} \mathbf{1}}-1.00 \mathrm{kcal} \mathrm{mol}^{-1}\right)$ whereas the corresponding reaction for oxygen $(\mathbf{3 b} \rightarrow \mathbf{7 b})$ is calculated to be considerably endothermic. Formation of the product $\mathbf{7 b}$ is therefore calculated to be highly unfavourable. This difference arises entirely from differences in the energies of the transitions states $\mathbf{T} 2$ and the resulting intermediates 6. For cyclisation of the oxygen analogue $\mathbf{5 b}$, the activation energy for formation of the transition state $\left(\boldsymbol{\Delta}_{\mathbf{5 T 2}}\right)$ is much higher $\left(\approx 11 \mathrm{kcal} \mathrm{mol}^{-1}\right.$ more than for $\left.\mathbf{5 a}\right)$, and the

Table 1 Gas phase MP2 calculated energy values $(\mathbf{G})$ and energy differences $(\Delta \mathbf{G})$ for the structures shown in Fig. 1

\begin{tabular}{|c|c|c|c|c|c|c|c|c|c|}
\hline \multirow[t]{2}{*}{ Entry } & \multirow[t]{2}{*}{$\mathbf{Y}$} & \multicolumn{4}{|l|}{ G (Hartrees) } & \multicolumn{4}{|c|}{$\Delta G\left(\mathrm{kcal} \mathrm{mol}^{-1}\right)$} \\
\hline & & 3 & T1 & 4 & 5 & $\Delta \mathbf{G}_{3 \mathrm{~T} 1}$ & $\Delta \mathbf{G}_{\mathrm{D} 1}$ & $\Delta \mathbf{G}_{34}$ & $\Delta \mathbf{G}_{36}$ \\
\hline 1 & a, $Y=S$ & -1115.825607 & -1115.779662 & -1115.796925 & -1115.789162 & 28.83 & 4.87 & 18.00 & 26.35 \\
\hline 2 & $\mathbf{b}, \mathrm{Y}=\mathrm{O}$ & -793.227336 & -793.178146 & -793.200781 & -793.189235 & 30.87 & 7.25 & 16.66 & 43.47 \\
\hline 3 & c, $\mathrm{Y}=\mathrm{N} . \mathrm{NO}$ & -902.358936 & -902.309764 & -902.330419 & -902.324790 & 30.86 & 3.53 & 17.89 & 25.46 \\
\hline \multirow[t]{2}{*}{4} & d, $\mathrm{Y}=\mathrm{CH} . \mathrm{NO}$ & -886.313231 & -886.271512 & -886.296828 & -886.291241 & 26.18 & 3.51 & 10.29 & 18.79 \\
\hline & & 5 & $\mathbf{T 2}$ & 6 & 7 & $\Delta \mathbf{G}_{5 \mathrm{~T} 2}$ & $\Delta \mathbf{G}_{6 \mathrm{~T} 2}$ & $\Delta \mathbf{G}_{67}$ & $\Delta \mathbf{G}_{\mathbf{R} 1}$ \\
\hline 5 & a, $Y=S$ & -1115.789162 & -1115.756116 & -1115.783613 & -1115.827202 & 20.74 & 17.25 & 27.35 & -1.00 \\
\hline 6 & $\mathbf{b}, \mathrm{Y}=\mathrm{O}$ & -793.189235 & -793.138252 & -793.158064 & -793.200810 & 31.99 & 12.26 & 26.82 & 16.65 \\
\hline 7 & c, $\mathrm{Y}=\mathrm{N} . \mathrm{NO}$ & -902.324790 & -902.283529 & -902.318370 & -902.373378 & 25.89 & 21.86 & 34.52 & -9.06 \\
\hline 8 & d, $\mathrm{Y}=\mathrm{CH} . \mathrm{NO}$ & -886.291241 & -886.235227 & -886.283283 & -886.342460 & 35.15 & 30.16 & 37.13 & -18.34 \\
\hline
\end{tabular}


Fig. 2 Generalised energy profile for the conversion of the mesoionic tetrazoles $\mathbf{3 c}, \mathbf{d}$ to the $\mathrm{N}$-oxides 9c, $\mathbf{d}$

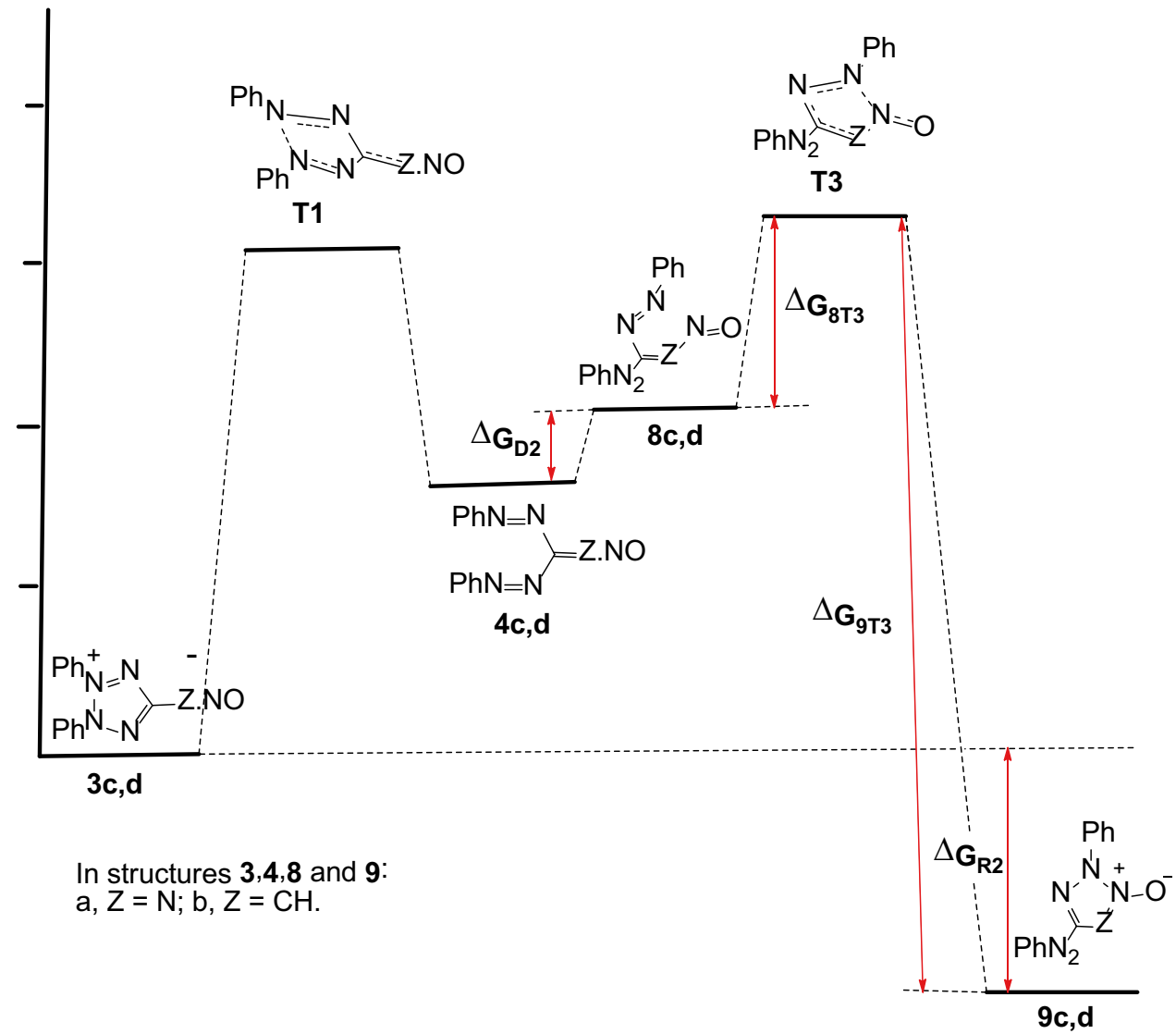

resulting intermediate $\mathbf{6 b}$, relative to $\mathbf{5 b}$, is also correspondingly higher in energy $\left(\approx 16 \mathrm{kcal} \mathrm{mol}^{-1}\right.$ more than for $\left.\mathbf{6 a}\right)$. This detracts from the overall energy of reaction $\left(\Delta \mathbf{G}_{\mathbf{R} 1}\right)$.

The cyclisations of the nitrogen and carbon species $\mathbf{5} \mathbf{c}, \mathbf{d}$ merit comment although these derivatives have an alternative, more favourable, mode of cyclisation (Scheme 2). The cyclisation of the imine $\mathbf{5 c}$ is a little less favourable than for the sulphur species 5a. The activation energy is higher $\left(\Delta \mathbf{G}_{\mathbf{5 T 2}} 25.89 \mathrm{kcal} \mathrm{mol}^{-1}\right)$ but overall, the transformation $\mathbf{3 c} \rightarrow \mathbf{7 c}$ is exothermic $\left(\boldsymbol{\Delta} \mathbf{G}_{\mathbf{R} \mathbf{1}}-9.06 \mathrm{kcal} \mathrm{mol}^{-1}\right)$. For the carbon analogue $\mathbf{5 d}$, the activation energy is highest $\left(\Delta \mathbf{G}_{\mathbf{5 T 2}}\right.$ $35.15 \mathrm{kcal} \mathrm{mol}^{-1}$ ), but much of this is regained on formation of $\mathbf{6 d}$, and the tautomerism $\mathbf{6 d} \rightarrow \mathbf{7 d}$ is particularly favourable. Overall, the transformation $\mathbf{3 d} \rightarrow \mathbf{7 d}$ is calculated to be highly exothermic $\left(\boldsymbol{\Delta} \mathbf{G}_{\mathbf{R} \mathbf{1}}-18.34 \mathrm{kcal} \mathrm{mol}^{-1}\right)$; a contribution to this overall energy gain is the lower stabilisation $\left(\approx 7 \mathrm{kcal} \mathrm{mol}^{-1}\right)$ of the polar precursor $3 \mathbf{d}$ by carbon, as discussed above.
Figure 2 shows the generalised energy profile for the alternative ring-opening/ring-closure reactions of the mesoionic derivatives $\mathbf{3 c}(\mathrm{Z}=\mathrm{N})$ and $\mathbf{3 d}(\mathrm{Z}=\mathrm{CH})$. The initial valence tautomerism $(\mathbf{3} \rightleftharpoons \mathbf{4})$ is identical to that in Fig. 1. The rotamers 8 then recyclise, employing the nitroso functions, to give the $\mathrm{N}$-oxide products $\mathbf{9}$ via transition states T3. In both cases, the calculated activation energies $\left(\Delta \mathbf{G}_{\mathbf{8 T 3}}\right)$ are low (12-13 kcal mol $\left.{ }^{-1}\right)$, and the overall reactions $\left(\Delta \mathbf{G}_{\mathbf{R 2}}\right)$ are exothermic (-13.66 and $-22.83 \mathrm{kcal} \mathrm{mol}^{-1}$ respectively) (Table 2). As noted previously, the reaction of the carbon analogue $\mathbf{3 d}$ is more exothermic, and this is attributable to the lower stabilisation of the mesoionic precursor $\mathbf{3 d}$ by the exocyclic carbon atom.

\section{Aqueous phase MP2-PCM calculations}

The energies and energy differences shown in Tables 1 and 2 relate to the gas phase. It is of interest to investigate the
Table 2 MP2 calculated energy values $(\mathbf{G})$ and energy differences $(\boldsymbol{\Delta} \mathbf{G})$ for the structures shown in Fig. 2

\begin{tabular}{|c|c|c|c|c|c|c|c|c|}
\hline \multirow[t]{2}{*}{ Entry } & \multirow[t]{2}{*}{$\mathbf{Z}$} & \multicolumn{3}{|l|}{ G (Hartrees) } & \multicolumn{4}{|c|}{$\Delta \mathrm{G}\left(\mathrm{kcal} \mathrm{mol}^{-1}\right)$} \\
\hline & & 8 & $\mathbf{T 3}$ & 9 & $\Delta \mathbf{G}_{\mathrm{D} 2}$ & $\Delta \mathbf{G}_{\mathbf{8 T 3}}$ & $\Delta \mathbf{G}_{\mathbf{9 T 3}}$ & $\Delta \mathbf{G}_{\mathrm{R} 2}$ \\
\hline 1 & $\mathrm{Z}=\mathrm{N}$ & -902.324790 & -902.304881 & -902.380707 & 3.54 & 12.49 & 47.53 & -13.66 \\
\hline 2 & $\mathrm{Z}=\mathrm{CH}$ & -886.291241 & -886.270514 & -886.349611 & 3.51 & 13.01 & 49.63 & -22.83 \\
\hline
\end{tabular}


Table 3 Solvated MP2-PCM calculated energy values $(\mathbf{G})$ and energy differences $(\boldsymbol{\Delta G})$ for the structures shown in Fig. 1

\begin{tabular}{|c|c|c|c|c|c|c|c|c|c|}
\hline \multirow[t]{2}{*}{ Entry } & \multirow[t]{2}{*}{$\mathbf{Y}$} & \multicolumn{4}{|l|}{ G (Hartrees) } & \multicolumn{4}{|c|}{$\Delta \mathrm{G}\left(\mathrm{kcal} \mathrm{mol}^{-1}\right)$} \\
\hline & & 3 & $\mathbf{T 1}$ & 4 & 5 & $\Delta \mathrm{G}_{\mathbf{3 T 1}}$ & $\Delta G_{D 1}$ & $\Delta G_{34}$ & $\Delta G_{36}$ \\
\hline 1 & a, $Y=S$ & -1115.856429 & -1115.791484 & -1115.805278 & -1115.798086 & 40.75 & 4.51 & 32.10 & 37.74 \\
\hline 2 & $\mathbf{b}, \mathrm{Y}=\mathrm{O}$ & -793.242707 & -793.192380 & -793.208322 & -793.199913 & 37.86 & 5.28 & 21.58 & 44.66 \\
\hline 3 & c, $\mathrm{Y}=\mathrm{N} . \mathrm{NO}$ & -902.396906 & -902.325922 & -902.339817 & -902.335071 & 44.54 & 2.98 & 35.82 & 40.51 \\
\hline 4 & d, $\mathrm{Y}=\mathrm{CH} . \mathrm{NO}$ & $\begin{array}{c}-886.353005 \\
\mathbf{5}\end{array}$ & $\begin{array}{c}-886.287863 \\
\mathbf{T 2}\end{array}$ & $\begin{array}{c}-886.306872 \\
\mathbf{6}\end{array}$ & $\begin{array}{c}-886.302128 \\
7\end{array}$ & $\begin{array}{l}40.88 \\
\mathbf{\Delta G}_{\mathbf{5 T 2}}\end{array}$ & $\begin{array}{c}2.98 \\
\boldsymbol{\Delta G}_{\mathbf{6 T 2}}\end{array}$ & $\begin{array}{l}28.95 \\
\Delta \mathbf{G}_{67}\end{array}$ & $\begin{array}{l}34.03 \\
\Delta \mathbf{G}_{\mathbf{R} 1}\end{array}$ \\
\hline 5 & a, $Y=S$ & -1115.798086 & -1115.767854 & -1115.796287 & -1115.838391 & 18.97 & 17.84 & 26.42 & 11.32 \\
\hline 6 & $\mathbf{b}, \mathrm{Y}=\mathrm{O}$ & -793.199913 & -793.150897 & -793.171543 & -793.211805 & 30.76 & 12.96 & 25.26 & 25.67 \\
\hline 7 & c, $\mathrm{Y}=\mathrm{N} . \mathrm{NO}$ & -902.335071 & -902.295975 & -902.332344 & -902.386481 & 24.53 & 22.82 & 33.97 & 6.54 \\
\hline 8 & $\mathbf{d}, \mathrm{Y}=\mathrm{CH} . \mathrm{NO}$ & -886.302128 & -886.243052 & -886.298779 & -886.356081 & 37.07 & 34.97 & 35.96 & -1.93 \\
\hline
\end{tabular}

influence of a polar solvent on the energy profiles. Taking water as an example, we have calculated the water-solvated free energies using the PCM (polarised continuum model) method to simulate aqueous solvation. The results for the reaction sequence $\mathbf{3} \rightarrow \mathbf{7}$ are shown in Table 3 . A significant conclusion from these results is that solvent has little influence on the second phase of the reaction sequence $\mathbf{4} \rightarrow \mathbf{5} \rightarrow \mathbf{T} \mathbf{2} \rightarrow \mathbf{6} \rightarrow \mathbf{7}$ (Fig. 1). For the parameters $\Delta \mathbf{G}_{\mathbf{D}}$, $\Delta \mathbf{G}_{\mathbf{5 T 2}}$ and $\Delta \mathbf{G}_{\mathbf{6 7}}$, the lowering of energy differences by solvent is small and in the range $0.3-2.0 \mathrm{kcal} \mathrm{mol}^{-1}$. The only exception is $\mathbf{\Delta} \mathbf{G}_{\mathbf{5 T 2}}$ for $\mathrm{Y}=\mathrm{CH}$.CN (Entry 8) for which the energy difference is raised by solvent $\left(-1.92 \mathrm{kcal} \mathrm{mol}^{-1}\right)$. Interestingly, the energy values for the reverse activation energies $\Delta \mathbf{G}_{\mathbf{6 T 2}}$ are increased in the range $0.6-1.0 \mathrm{kcal} \mathrm{mol}^{-1}$ with the exception, again, of $\mathrm{Y}=\mathrm{CH} . \mathrm{CN}$ which increases by $4.8 \mathrm{kcal} \mathrm{mol}^{-1}$. Clearly, there is something a little different about the exocyclic CH.CN group, but overall, these small energy changes are of low significance and do not merit further discussion.

Solvation has a much greater effect on the first phase of the reaction sequence, i.e. $\mathbf{3} \rightarrow \mathbf{T} \mathbf{1} \rightarrow \mathbf{4}$ (Fig. 1). We have previously reported that for isomers 3 and $4(Y=O, S)$ aqueous solvation favours the cyclic mesoionic form by 10-15 kcal mol ${ }^{-1}[1]$. For the conjugated exocyclic groups ( $\mathrm{Y}=\mathrm{N} . \mathrm{NO}, \mathrm{CH} . \mathrm{NO}$ ), this solvation effect is greater. Table 4 shows the changes in calculated energy differences $(\Delta \mathbf{\Delta G})$ upon solvation together with the calculated gas phase dipole moments $(\mu)$. In Table 4 , the effect of solvation on the energy difference $\boldsymbol{\Delta} \mathbf{G}_{\mathbf{3 4}}$ is shown as $\boldsymbol{\Delta} \mathbf{\Delta} \mathbf{G}_{\mathbf{3 4}}$. The magnitude of the solvation effect $\left(\boldsymbol{\Delta} \boldsymbol{\Delta} \mathbf{G}_{\mathbf{3 4}}\right)$ does correlate with the magnitude of the dipole moment although the particularly low solvent effect on the oxygen analogue (Entry 2) is surprising. A similar variation is seen for the solvent effect $\left(\Delta \Delta \mathbf{G}_{3 T 1}\right)$ on the activation energy $\Delta \mathbf{G}_{\mathbf{3 T 1}}$. Although of no particular significance, it is interesting to compare $\Delta \Delta \mathbf{G}_{\mathbf{3 4}}$ and $\Delta \mathbf{\Delta} \mathbf{G}_{\mathbf{3 6}}$. The variations of these solvent effects are very similar and, since solvation has little effect on the intermediates 6 (Tables 1 and 3), this effect can also be attributed to stabilisation of the dipolar precursors 3.

The effect of solvation on the overall reaction energy $\Delta \mathbf{G}_{\mathbf{R} 1}$ (Fig. 1) is of some interest. In all cases, the effect of the aqueous environment $\left(\boldsymbol{\Delta} \boldsymbol{\Delta} \mathbf{G}_{\mathbf{R} 1}\right)$ (Table 4) adversely affects the reaction energy, but this can all be attributed to stabilisation of the mesoionic precursors 3. Again the smallest solvent effect is on the oxygen analogue (Entry 2), but this is not advantageous since the cyclisation $\mathbf{5} \rightarrow \mathbf{6}$ is particularly unfavourable compared to those of the S, N.NO and CH.NO analogues.

Similar solvation effects are seen for the transformations $\mathbf{8} \rightarrow \mathbf{9}$ (Fig. 2). MP2-PCM energy values for aqueous solvation are shown in Table 5. Comparison with Table 2 shows that aqueous solvation effects are small $\left(<3 \mathrm{kcal} \mathrm{mol}^{-1}\right)$ for the energies $\Delta \mathbf{G}_{\mathbf{D 2}}, \boldsymbol{\Delta} \mathbf{G}_{\mathbf{8 T 3}}$ and $\boldsymbol{\Delta} \mathbf{G}_{\mathbf{9 T 3}}$. As for the formation of the products $\mathbf{7}$, there is a significant aqueous solvent effect on the overall energy of reaction $\Delta \mathbf{G}_{\mathbf{R} 2}$, but this can again be almost entirely attributed to solvent stabilisation of the mesoionic precursors $\mathbf{3 c}, \mathbf{d}$. The solvent effects $\left(\boldsymbol{\Delta} \boldsymbol{\Delta} \mathbf{G}_{\mathbf{R} \mathbf{2}}\right)$ are $15.85(\mathrm{Z}=\mathrm{N})$ and $16.84(\mathrm{Z}=\mathrm{CH}) \mathrm{kcal} \mathrm{mol}^{-1}$, which are
Table 4 Calculated dipole moments and solvent effects

\begin{tabular}{|c|c|c|c|c|c|c|c|}
\hline \multirow[t]{2}{*}{ Entry } & \multirow[t]{2}{*}{$\mathbf{Y}$} & \multirow{2}{*}{$\begin{array}{l}\text { Dipole Moment } \\
\mu \text { (D) }\end{array}$} & \multicolumn{5}{|c|}{ Energy increase due to solvation } \\
\hline & & & $\Delta \Delta G_{34}$ & $\Delta \Delta \mathbf{G}_{3 \mathrm{~T} 1}$ & $\Delta \Delta \mathbf{G}_{36}$ & $\Delta \Delta \mathbf{G}_{\mathrm{R} 1}$ & $\Delta \Delta G_{R 2}$ \\
\hline 1 & $\mathbf{a}, \mathrm{Y}=\mathrm{S}$ & 14.8 & 14.10 & 11.92 & 11.39 & 12.32 & - \\
\hline 2 & $\mathbf{b}, \mathrm{Y}=\mathrm{O}$ & 12.5 & 4.92 & 6.99 & 1.19 & 9.02 & - \\
\hline 3 & c, $\mathrm{Y}=\mathrm{N} . \mathrm{NO}$ & 17.6 & 17.93 & 13.68 & 15.05 & 15.60 & 15.85 \\
\hline 4 & d, $\mathrm{Y}=\mathrm{CH} . \mathrm{NO}$ & 18.1 & 18.66 & 14.70 & 15.24 & 16.41 & 16.84 \\
\hline
\end{tabular}


Table 5 MP2-PCM calculated energy values $(\mathbf{G})$ and energy differences $(\boldsymbol{\Delta} \mathbf{G})$ for the structures shown in Fig. 2

\begin{tabular}{|c|c|c|c|c|c|c|c|c|}
\hline \multirow[t]{2}{*}{ Entry } & \multirow[t]{2}{*}{$\mathbf{Z}$} & \multicolumn{3}{|l|}{ G (Hartrees) } & \multicolumn{4}{|c|}{$\Delta G\left(\right.$ kcal mol $\left.^{-1}\right)$} \\
\hline & & 8 & $\mathbf{T 3}$ & 9 & $\Delta G_{D 2}$ & $\Delta \mathbf{G}_{\mathbf{8 T 3}}$ & $\Delta \mathbf{G}_{9 \mathrm{~T} 3}$ & $\Delta \mathbf{G}_{\mathrm{R} 2}$ \\
\hline 1 & $\mathrm{Z}=\mathrm{N}$ & -902.335071 & -902.313236 & -902.393414 & 2.98 & 13.70 & 50.31 & 2.19 \\
\hline 2 & $\mathrm{Z}=\mathrm{CH}$ & -886.302128 & -886.281437 & -886.362549 & 2.98 & 12.98 & 50.90 & -5.99 \\
\hline
\end{tabular}

consistent with the corresponding values for $\Delta \mathbf{\Delta} \mathbf{G}_{\mathbf{R} \mathbf{1}} 15.60$ and $16.41 \mathrm{kcal} \mathrm{mol}^{-1}$ (Table 4, Entries 3 and 4).

\section{Conclusions}

This MP2 study sheds some light on the paucity of known reactions of the mesoionic 2,3-disubstituted tetrazolium5-olates $3 \mathbf{b}$. The calculations indicate that the activation energies $\left(\boldsymbol{\Delta} \mathbf{G}_{\mathbf{3 T 1}}\right)$ for ring opening of the tetrazoles 3a-d differ by only a few kcal mol${ }^{-1}$ (Table 1 ). In view of experimental evidence that the derivatives $\mathbf{3 a}, \mathbf{c}$ and $\mathbf{d}$ are in equilibrium with their valence tautomers $\mathbf{4 a}, \mathbf{c}$ and $\mathbf{d}$, it is probable that the oxygen analogues $\mathbf{3 b}$ can also thermally equilibrate with the open chain form.

It would seem that the tautomer $\mathbf{4 b}$ has no accessible reaction pathway other than re-closure to the ring $\mathbf{3 b}$. The calculated activation energy $\left(\Delta \mathbf{G}_{5 \mathbf{T} 2}\right)$ for the electrocyclic ring formation $\mathbf{5} \rightarrow \mathbf{6}$ is much higher for the oxygen derivative $\mathbf{5} \mathbf{b}\left(31.99 \mathrm{kcal} \mathrm{mol}^{-1}\right)$ than for the known reaction of the sulphur analogue 5a $\left(20.74 \mathrm{kcal} \mathrm{mol}^{-1}\right)$ (Table 1). It is possible that other thermal pathways may be accessible to the tautomer $\mathbf{5 b}$ at high temperature; there is no evidence that this has been investigated. The tautomer $\mathbf{5 b}$ may also be trappable by appropriate alkenes and alkynes.

The calculated effects of aqueous solvation on the reaction energetics shown in Figs. 1 and 2 are small with the exception of stabilisation of the mesoionic precursors 3 . Only the energy differences directly related to the energy of the precursors $\mathbf{3}$ are significantly increased by solvation (i.e.

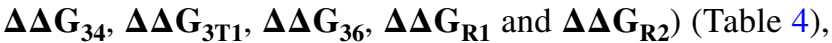
and these are consistently attributable to the solvent effect on the precursors 3 . This is in accord with their polarity and the calculated dipole moments (Table 4). Clearly, for reactions of these species, the polarity of the solvent should be minimised.

\section{Computational details}

Calculations were performed using the Gaussian 16 program [17] at the ab initio Moller-Plesset MP2 level of theory [18]. The correlation consistent aug-cc-pVDZ (ACCD) basis set was used [19, 20]. All geometry optimizations were followed by frequency calculations to establish the nature of the stationary point and to calculate the ZPE and thermal corrections to Gibbs free energy. All obtained transition states have one imaginary frequency which connects the appropriate reactant and product. All minima on the potential energy surface have no imaginary frequencies. All calculations were performed for the gas phase and for the water environment modelled via polarizable continuum model (PCM) [21].

Supplementary information The online version contains supplementary material available at https://doi.org/10.1007/s11224-021-01841-8.

Funding Computational Grant G36-9 from the Interdisciplinary Centre for Mathematical and Computational Modelling at Warsaw University (ICM UW).

Data Availability Additional data (geometric parameters and Gibbs free energies of optimized molecules) are available as Supplementary Information.

\section{Declarations}

Competing interests The authors declare no competing interests.

Open Access This article is licensed under a Creative Commons Attribution 4.0 International License, which permits use, sharing, adaptation, distribution and reproduction in any medium or format, as long as you give appropriate credit to the original author(s) and the source, provide a link to the Creative Commons licence, and indicate if changes were made. The images or other third party material in this article are included in the article's Creative Commons licence, unless indicated otherwise in a credit line to the material. If material is not included in the article's Creative Commons licence and your intended use is not permitted by statutory regulation or exceeds the permitted use, you will need to obtain permission directly from the copyright holder. To view a copy of this licence, visit http://creativecommons.org/licenses/by/4.0/.

\section{References}

1. Ramsden CA, Oziminski WP (2019) Tet Lett 60:150876

2. Fischer E, Besthorn E (1882) Ann 212:316

3. Bamberger E (1898) Chem Zentralbl 2:1050

4. Bamberger E (1911) Ber 44:3743

5. Bamberger E, Padova R, Ormerod E (1926) Ann 446:260

6. Ollis WD, Ramsden CA (1976) Adv Heterocycl Chem 19:1

7. Neugebauer FA, Fischer H (1980) Chem Ber 113:1226

8. Araki S, Mizuya J, Butsugan Y (1985) J Chem Soc Perkin Trans I:2439

9. McDonald WS, Irving HMNH, Raper G, Rupainwar DC (1969) J Chem Soc D Chem Commun 392

10. Boyd GV, Norris T, Lindley PF (1975) J Chem Soc Chem Commun 100 
11. Boyd GV, Norris T, Lindley PF (1976) J Chem Soc Perkin Trans I: 1673

12. Ollis WD, Stanforth SP, Ramsden CA (1985) Tetrahedron 41:2239

13. Smith IS (1972) MSc Thesis (University of Sheffield)

14. Ollis WD, Ramsden CA (1976) Adv Heterocycl Chem 19:85

15. Hanley RN, Ollis WD, Ramsden CA, Smith IS (1979) J Chem Soc Perkin Trans I:744

16. Moderhack D (2016) Heterocyles 92:185

17. Gaussian 16, Revision C.01, Frisch MJ, Trucks GW, Schlegel HB, Scuseria GE, Robb MA, Cheeseman JR, Scalmani G, Barone V, Petersson GA, Nakatsuji H, Li X, Caricato M, Marenich AV, Bloino J, Janesko BG, Gomperts R, Mennucci B, Hratchian HP, Ortiz JV, Izmaylov AF, Sonnenberg JL, Williams-Young D, Ding F, Lipparini F, Egidi F, Goings J, Peng B, Petrone A, Henderson T, Ranasinghe D, Zakrzewski VG, Gao J, Rega N, Zheng G, Liang W, Hada M, Ehara M, Toyota K, Fukuda R, Hasegawa J, Ishida M, Nakajima T, Honda Y, Kitao O, Nakai H, Vreven T, Throssell
K, Montgomery JA Jr, Peralta JE, Ogliaro F, Bearpark MJ, Heyd JJ, Brothers EN, Kudin KN, Staroverov VN, Keith TA, Kobayashi R, Normand J, Raghavachari K, Rendell AP, Burant JC, Iyengar SS, Tomasi J, Cossi M, Millam JM, Klene M, Adamo C, Cammi R, Ochterski JW, Martin RL, Morokuma K, Farkas O, Foresman JB, Fox DJ (2016) Gaussian, Inc., Wallingford CT

18. Møller C, Plesset MS (1934) Phys Rev 46:618

19. Dunning TH Jr (1989) J Chem Phys 90:1007

20. Woon DE, Dunning TH Jr (1993) J Chem Phys 98:1358

21. Cossi M, Barone V, Cammi R, Tomasi J (1996) Chem Phys Lett 255:327

Publisher's Note Springer Nature remains neutral with regard to jurisdictional claims in published maps and institutional affiliations. 